\title{
Technology Sharing Decisions Digital Technologies and Sharing Economy
}

\author{
Imelda Ukpabio, Mirabel Omoruyi, Anietie G. Ukpabio
}

\begin{abstract}
As the conversation regarding sharing as well as economic alliance has heightened around the phrase "sharing economy", the concept of digital sharing economy emanates more and more significantly. The objective of the paper is to support sharing of digital technologies and forums in order to achieve a sustainable shared economy. In addition, the research uses qualitative research methodology that relies extensively on literature review from assembled academic, peer - reviewed journal articles to improve comprehensive understanding on the impact of digital technologies on sharing economy. The research findings indicate that utilization of digital technologies enhances sharing economy and that the rising of digital sharing forums implies more individuals will be linked to resources closer to them as well as connected to each other. In conclusion, digital technologies in sharing economy offers significance collective solutions to areas such as employment and income generation; natural resources stewardship; asset sharing; knowledge exchange, education and professional establishment; crowd funding; new community - driven technological revolutions; disaster relief; and civic engagement.
\end{abstract}

Keywords: Sharing Economy, Digital Technologies, Digital Platforms, Collective consumption, Collective Economy

DOI: $10.7176 /$ ISDE/12-1-04

Publication date: January $31^{\text {st }} 2021$

\section{Introduction}

Discussions regarding sharing as well as economic alliance has revolved around the phrase "sharing economy". People have been always sharing resources and therefore cannot be regarded as new narrative. With availability of digital technologies such as internet, mobile devices and establishment of online forums, content and resources sharing as well offers users new ways of dispersion (Kowalska, 2019).

The expression "sharing economy" is a comprehensive idea that is sometimes considered as access - based utilization, collective utilization, or commercial sharing structure (Mikołajewska, 2019). Nevertheless, what is frequent amidst the terms is the importance of the utilization of idling resources and how this has profited both individual users as well as the society. Sharing economy can be regarded as an umbrella that entails various ICT establishments as well as technologies that countersign peer to peer sharing of goods and services via use of digital devices and online forums between particulars (Ferraro \& Conway, 2020).

The sharing economy influence is immense and the apprehension is expanding yearly. According to Oskam (2019), Airbnb holds approximately 500,000 visitors each and every night while $45 \%$ of United States adults are frequent with the sharing economy idea. Conventional studies indicates that approximately $24 \%$ of United Kingdom population has utilized internet technologies to share resources or assets (Russell, 2019). With the increasing use of digital technologies idea, it suggests that very few organizations and industries are immune from its capable effect and change on sharing economy (Deleris \& Aonghusa, 2020).

Corporations and organizations encounter problems on how to survive with the impact of digital content escalation within their processes, products and services. Sharing as an idea and utilization of resources is certain event that all can agree is a positive occurrence, both from economical and sustainable point of view. From various city outlooks, it is asserted that it is decisive to configure a city that is capable to engross, alter and retaliate to changes so as to survive with expounding urbanization (Foxhall, 2015). Even though Information \& Communication Technologies (ICT) are essential movers of enterprises and might probably provide citizens with moments, the importance of digital technologies in troublesome sharing economy remains ambiguous.

This paper aims to support sharing of digital technologies and forums for enticing an attractive successful shared economy. Digital technologies are resourceful in building sharing economy that is troublesome. The paper offers valuable perception regarding to the digital technologies in sharing economy context by tackling sharing economy difficulties.

\section{Review of relevant literature}

\subsection{Sharing Economy}

The expression 'sharing economy' cite to the area of sharing resources in a systematic way. Provided the progressing procedure of digitization, social network extension as well as Web 2.0, the idea of sharing has undergone a substantial development in the recent years (Lewandowska, 2019). Owing to the engagement of several business models, product segments and markets, reaching at a frequent definition is immense. Sharing economy is an economic replica for sharing underexploited assets for financial or non - financial profits (Guasoni 
\& Wang, 2018). Sharing economy is also interpreted as peer - to - peer based activity of acquiring, awarding, or sharing the acquisition to goods and services, harmonized via community - based online services (Dolnicar, 2020).

Bhatt, 2016, also highlighted the significance of digital technology as well as forums, inclusive of monetized or non-monetized exchange, as the justification for a new way of offering goods and services. In addition, Szemerédi \& Tatay, 2020 argues that sharing economy is the desirability in picking underused assets and establishing them to be attainable online to a community, leading to a declined demand for ownership of those assets. This hypothesis is inclusive of five major components, namely; underutilized assets, community, value establishment, online accessibility as well as curtailed demand for ownership.

Weber, 2015, provides a comprehensive view regarding sharing economy which comprises various non ownership manifestation of utilization activities such as collective utilization and access - based utilization. Collective utilization is regarded as people synchronizing accession and distribution of resources for a cost or other remuneration, in which numerous sharing activities are eliminated, since no remuneration of the supplier is involved (Olelenku, 2018). In addition, gifting is eliminated, as it involves a permanent ownership transfer. This interpretation of collective utilization is perceived as a median ground connecting sharing and marketplace trading, with components of both (Carothers \& Hucks, 2014). Collective utilization as peer -to - peer based scheme of acquiring, providing, or sharing acquisition to goods or services is synchronized via community - based online services (Brambilla, Picone, Amoretti \& Zanichelli, 2014). It involves undertakings like lending, gifting, bartering, renting as well as swapping in various classifications such as redistribution markets, product service system, and collective life - styles.

Access - based utilization is viewed as negotiations that can be arbitrated. However, no ownership transfer takes place and variations from sharing since concentration is more on the arbitration role (Namuganga, 2019). While both these perspectives poses indistinguishable features, they concentrate on various features of the expression sharing economy. Boar, Bastida \& Marimon, 2020, connotes that utilizing content as well as co citation analysis, culminates the concentration of sharing economy literature on sharing economy nature, business replicas, as well as sustainability development, particularly in the field of hospitality as well as tourism.

\subsection{Digital Sharing Economy}

Digital technologies enhances sharing economy and thus sharing heavily rely on ICT (YunSeungKo, 2014). By offering a technological framework for sharing, ICT has fashioned new configurations of social connections that can be deluxe to social connections, sufficient enough to execute economic activities. Technology role, inclusive of social networking forums, new algorithms, big data as well as cloud computing, has led to dispensation of sharing economy as technological occurrence and marking it as "digital complementing economy" or "economy forum" (Möhlmann, Teubner \& Graul, 2019).

Additionally, various studies cite peer - to - peer category of negotiation or networking in the sharing economy relies on technological features that lead to the expression peer economy (Pinson, Moret, Baroche \& Papakonstantinou, 2020). Conspicuous popularity and growth of the sharing economy owes to its enhancing individuals to conduct economic pursuit in their peer networks as well as to create "resourceful" social relationships. Various peers sharing system players include; Peer - to - Business (P2B), Business - to - Peer (B2P) as well as Business - to - Business (B2B) models. For instance, in B2P market, an organization offers the forum and contributes the resource to be divided. The forum giver, i.e. 'commercial' sharing organization, lies on one side of the negotiation, as antagonistic to P2P replica in which peers emanate as service providers who 'permit' access to and 'share' their possessed resource.

'Sharing' is perceived in the perception of sharable resources. This insinuate that utilizing a resource can be acknowledged as a 'service' in a sharing system and accepting this service might engage either direct or indirect financial remuneration (Moghe, Chaturvedi \& Lakkadwala, 2015). Generally, two sharing services types with contemplation to the economic value can be conjectured: one that engages money flow (for - fee sharing) and another one that engages only indirect financial value acquired via not paying for the services obtained (not for fee sharing). Consequently, the digital sharing economy can comprise systems that are completely founded on non - monetary value idea such as time bank plans. If not - for - fee sharing, services are either free or in configuration of remuneration needed relies on services as well as resources type provided by a specific forum (Ozanne, 2019). This may be inclusive of formal cooperation with time, skills as well as other resources.

A precise extensive illustration for the sharing economy that is capable of enclosing its typical characteristics must probably narrate the system, actors engaged in it, activities and negotiations. Consequently, 'digital sharing economy' is connoted as resource allotment system, established on sharing enactments, that is enhanced by Information and Communication Technology (ICT) and synchronized via individuals participation as well as feasibly commercial businesses with the objectives to offer non - permanent acquisition to resources that engages either indirect or direct monetary value (Mkrttchian \& Vertakova, 2019). The sharing economy concept is the technological proceeds and shift in behaviour of the consumer's in relation to sharing assets with intruders, promoting trust and willingness to cooperate. 


\section{Methodology and Method}

This research utilizes literature review from assembled academic, peer - reviewed journal articles to alleviate comprehensive understanding on digital technologies and sharing economy and casting light on modulation among authors within a research field (Charkawi, 2018). In order to integrate the academic conversation regarding the explanation of sharing economy, the research pilots a literature review ensued by qualitative content exploration using a grounded theory approach. Additionally, the coverage of Scopus as well as Web of Science indulges academic journals over books, reports as conference proceedings within the social sciences as well as humanities (Jones, 2020).

The research conducts a mapping out study to reinforce the recognition of keywords utilized in the subsequent database research of Web of Science and Scopus. The research further choses the search query "Collective utilization' OR 'Sharing Economy" or 'Collective Economy' OR 'Digital Technologies' to account for the certainty that some authors utilized the terms conversely. Furthermore, the study also incorporates scoping study of the ten highest cited articles in Web of Science and Scopus, which yielded 20 articles after considering the duplicates. These articles were read to refine other associated expressions regarding sharing economy. The scoping study ensued thirty associated expressions (Appendix A), which were utilized to implement the successive database search connecting to the sharing economy.

The database search carried out comprised articles commencing January 1, 1978. Results were restricted to peer - reviewed journals and academic articles written in English. The search outcome gave back 2081 articles, inclusive of duplicates between databases, 938 from Web of Science and 1143 from Scopus (Appendix A). The titles, abstracts and keywords were evaluated to substantiate significance of this study based on debarring criteria purposive by our scoping study. The review deferred 213 articles from Web of Science (467 inclusive of duplicates) and 251 articles from Scopus. Among these, second phase of review was carried out by eliminating: articles restricted to full access as PDF; articles imitated between databases; or, articles improperly catalogued based on the literature type, disputing language between the databases. Our final illustrative comprised 235 academic, peer reviewed journal articles which forms the basis for next phase of analysis.

On data analysis, the study utilized the Qualitative Content analysis, first on the defining sharing economy in each academic article. Nevertheless, some authors consolidate expressions, in segments, owing to the progressive acceptable confusion. For instance, Garcia, 2018, connotes that; "collective utilization is submerged within the "sharing economy" which engages access - based utilization of products or services that can be online or as well offline." Under this instance, the text could be encrypted to various cases comprising "sharing economy", "collective utilization" and "access - based utilization". Secondly, once the encryption of the cases were concluded, analysis commenced on defining sharing economy.

\section{Findings}

The established digital technologies as dimensions of the sharing economy were encrypted. The findings are not prescriptive but instead descriptive. Of significance to the establishment of characteristics that enlighten a definition on sharing economy, the study reports on the digital technologies dimensions.

Sharing economy is broadly illustrated as being Information Communication Technology - enabled. While authors designate that sharing is not a brand new occurrence, the 'newness' of the sharing economy appear to stem from the utilization of technology to expedite the systematic exchange or mediation between users as well as providers, generating a two or numerous - sided market (Cooper, 2017). In turn, this curtails the negotiations costs related with sharing among strangers (Saragh, 2015). Technology assists to curtail these negotiations costs by:

- $\quad$ Refining access to information

- $\quad$ Stimulating payments

- $\quad$ Raising convenience

- $\quad$ Stimulating arbitration between providers as well as users

- $\quad$ Stimulating a review system or reputation

The fundamental descriptive element for this spiral economic competence within our dataset is preliminary connected to technological revolution. While offline sharing exists, majority of sharing organizations use some manifestation of technology. The internet, social media, smartphones as well as algorithms are debated with respect to forum intermediation, piloting about the competence gains attributed to the sharing economy (Yeung, 2018). Our analysis illustrates that many expressions are utilized in literature to express the scope to which the sharing economy is Information Communication Technology - enabled. The diversity of views used in expressing the means and the extent of digital technologies intermediation of sharing economy sums up to the acceptable confusion. For instance, authors utilize the expressions 'web' and 'internet' interchangeably; nevertheless, there is a significance distinction: the web delineates the information sharing replica that is built on the top of internet whereas the internet delineates networking infrastructure. Moreover, complementary digital as well as smart technologies, both 'smart' and 'digital' focus on ICT integration whereas 'smart' also recognizes the link to systems, infrastructure as well as stipulate an underlying environmental incentive (Mallikarjuna, Khanam \& 
Poonia, 2017).

The extent of conversation in literature regarding these dimensions call for questions concerning the type, extent or form of digital technologies or Information Communication Technology - enabled mediation fascinating place in the sharing economy as well as the successive effect on perceiving claimed sustainability outcomes.

Digital technologies - number of articles as well as frequency of appearance on dataset

\begin{tabular}{|c|c|c|}
\hline Expressions & Articles & Frequencies \\
\hline Online & 52 & 132 \\
\hline Internet & 43 & 69 \\
\hline Technology & 40 & 78 \\
\hline Smartphone & 11 & 15 \\
\hline Smart Phone App & 9 & 19 \\
\hline Social Media & 8 & 21 \\
\hline Website & 7 & 9 \\
\hline Social Networks & 5 & 6 \\
\hline ICT & 5 & 6 \\
\hline Internet-based & 4 & 4 \\
\hline Mobile Technology & 4 & 4 \\
\hline Web 2.0 & 4 & 5 \\
\hline Online Community & 3 & 3 \\
\hline Online Platform & 3 & 3 \\
\hline Virtual & 3 & 6 \\
\hline Internet-mediated & 2 & 2 \\
\hline Technology-driven & 2 & 2 \\
\hline 3rd Industrial Revolution & 2 & 2 \\
\hline Big Data & 2 & 2 \\
\hline Digital Platform & 2 & 2 \\
\hline Mobile Device & 2 & 2 \\
\hline Online Marketplace & 1 & 1 \\
\hline Web Platform & 1 & 1 \\
\hline
\end{tabular}

\section{Conclusion}

Digital sharing economy is escalating significance collective solutions comprise effects in developing countries (Niankara, 2020). The areas include: employment and income generation; natural resources stewardship; asset sharing; exchanging knowledge, education as well as professional establishment; crowd funding; new community - driven technological revolutions; disaster relief; and civic engagement. The most pressing requirements that are conventionally being tackled by the digital sharing economy comprise employment and income generations. These dimensions are where major solutions survive today; nevertheless we also predict the digital sharing economy enhanes education significance as well as job training objectives.

The research also insinuates that sharing as well as cooperation present prospective quick ways to heighten living standards by establishing access instead of ownership (Foxhall, 2015). For instance, the growth of Wikipedia to developing countries is influencing millions of readers who can obtain information not readily accessible in their local communities. Instances such as Wikimapa exhibit how perspective that erect, coordinate as well as share distributed resources in low - income communities can be fabricated in areas where private or public institutions do not outstretch.

An expounding interest is emanating globally to expedite social innovations via digital cooperative solutions. Escalating, open source has been situated, adjusted or established in developing countries. Additional social entrepreneurs with powerful international encounters position their talents to generate solutions that tackle social needs in their home countries (Kowalska, 2019). Confirmation of this tendency can be established at the "hackathon" occurrences equipping to entrepreneurs such as Startup Weekend or in the propagation of business accelerators as well as incubators of all types that assist social entrepreneurs assemble their businesses as well as obtain capital to grow.

These elements are subscribing to expeditiously expounding network of players that can speedily adjust digital forums and deploy them to new state of affairs. Even if the encounters may not be that systematic at first, we must recall that Wikipedia was originally dishonored before finally becoming globally welcomed as the immense encyclopedia in the world. In the same process, some of the digital cooperative solutions forms may necessitate from ad-hoc experiments to emanate the most conspicuous way to tackle a comprehensive variety of establish - mental challenges (Weber, 2015).

The research exemplify that the digital sharing economy can enhance a new replica for development. Digital cooperative solutions fabricate on the substantial encounter that various communities build the "solidarity" and 
"self - help" elements connected with the sharing economy (Ozanne, 2019). When people cooperate via digital forums, they suit empowered as well as achieve important social outcomes. This may as well comprise essential inference for how international development is dispatched in future. For instance, donor originations may resolve to shift their perspective by recognizing social issues they want to conclude, and convoking multi-stakeholder communities as well as forums to cooperatively find the best answer (Boar, Bastida \& Marimon, 2020). This would be important shift from the contemporary replica where social capital suppliers handpick organizations to provide particular projects. Therefore, via our research we were capable to establish that the rising of digital sharing forums implies more individuals linked to resources closer to them as well as connected to each other.

\section{References}

Bhatt, S. (2016). The Sharing Economy: Information Cascades, Network Effects and Power Laws. How Digital Communication Technology Shapes Markets, 105-118. doi:10.1007/978-3-319-47250-8_6

Boar, A., Bastida, R., \& Marimon, F. (2020). A Systematic Literature Review. Relationships between the Sharing Economy, Sustainability and Sustainable Development Goals. Sustainability, 12(17), 6744. doi:10.3390/su12176744

Brambilla, G., Picone, M., Amoretti, M., \& Zanichelli, F. (2014). An Adaptive Peer-to-Peer Overlay Scheme for Location-Based Services. 2014 IEEE 13th International Symposium on Network Computing and Applications. doi:10.1109/nca.2014.35

Carothers, S. C., \& Hucks, D. C. (2014). Connecting the Collective. New Visions of Collective Achievement, 116132. doi:10.1007/978-94-6209-809-1_8

Cooper, L. G. (2017). Personalization and Technology-Enabled Marketing. Managing in the Information Economy, 165-184. doi:10.1007/978-0-387-36892-4 7

Deleris, L., \& Mac Aonghusa, P. (2020). Behaviour Change for the Sharing Economy. Analytics for the Sharing Economy: Mathematics, Engineering and Business Perspectives, 173-187. doi:10.1007/978-3-030-35032$1 \_11$

Dolnicar, S. (2020). Sharing economy and peer-to-peer accommodation A perspective paper. doi:10.31235/osf.io/rqdhw

El Charkawi, H. G. (2018). Review of Literature Update Index, A New Index For Peer Reviewed Articles. Biomedical Journal of Scientific \& Technical Research, 11(5). doi:10.26717/bjstr.2018.11.002150

Ferraro, P., \& Conway, D. (2020). Distributed Ledger Technologies and the Collaborative Economy. Analytics for the Sharing Economy: Mathematics, Engineering and Business Perspectives, 95-107. doi:10.1007/978-3$030-35032-1$

Foxhall, L. (2015). Village to City: Staples and Luxuries? Exchange Networks and Urbanization. Mediterranean Urbanization 800-600 BC. doi:10.5871/bacad/9780197263259.003.0011

Garcia, L. (2018). Research on the Integration and Utilization of Personal Non-tangible Idle Resources under Sharing Economy. 2018 International Conference on Economics, Finance, Business, and Development (ICEFBD 2018). doi:10.25236/icefbd.18.080

Guasoni, P., \& Wang, G. (2018). Sharing Profits in the Sharing Economy. SSRN Electronic Journal. doi: $10.2139 /$ ssrn.3278274

John Russell, E. (2019). The United Kingdom. World Population and World Food Supplies, 24-58. doi:10.4324/9780429296802-2

Jones, M. (2020). LITERATURE REVIEW. Accounting Journals: Scopus, Web of Science, SCImago, 9-15. doi:10.2478/9788395669675-002

Kowalska, S. (2019). Behaviors of consumers regarding the development of sharing economy. Zeszyty Naukowe Uniwersytetu Szczecińskiego Problemy Transportu i Logistyki, 47, 39-52. doi:10.18276/ptl.2019.47-04

Lewandowska, A. (2019). Social economy and sharing economy in creating sustainable development SUMMARY. Zeszyty Naukowe Uniwersytetu Szczecińskiego Problemy Transportu i Logistyki, 48, 7-16. doi:10.18276/ptl.2019.48-01

Mallikarjuna, M., Khanam, A., \& Poonia, A. (2017). Smart grids: A perspective on the integration and encapsulation of power energy systems with ICT systems — New research directions and challenges. 2017 International Conference On Smart Technologies For Smart Nation (SmartTechCon). doi:10.1109/smarttechcon.2017.8358452

Mikołajewska-Zając, K. (2019). The rhetoric of sharing: managerial literature on the sharing economy. Handbook of the Sharing Economy, 362-374. doi:10.4337/9781788110549.00039

Mkrttchian, V., \& Vertakova, Y. (2019). Digital Sharing Economy. International Journal of Innovation in the Digital Economy, 10(2), 40-53. doi:10.4018/ijide.2019040103

Moghe, U., Chaturvedi, B., \& Lakkadwala, P. (2015). Cloud Secure Resource Sharing Algorithm from Object Based Sharable Environment. 2015 4th International Conference on Reliability, Infocom Technologies and Optimization (ICRITO) (Trends and Future Directions). doi:10.1109/icrito.2015.7359264 
Möhlmann, M., Teubner, T., \& Graul, A. (2019). Leveraging trust on sharing economy platforms: reputation systems, blockchain technology and cryptocurrencies. Handbook of the Sharing Economy, 290-302. doi:10.4337/9781788110549.00033

Namuganga, N. (2019). Ownership, access and collaborative modalities. Handbook of the Sharing Economy, 6161. doi:10.4337/9781788110549.00011

Niankara, I. (2020). Research Data Recycling through Open Sharing and Reuse: A Case Study of Sustainable Digital Good Consumption in the Sharing Economy. doi:10.20944/preprints202007.0035.v1

Olelenku, J. (2018). Research on the Integration and Utilization of Personal Non-tangible Idle Resources under Sharing Economy. 2018 International Conference on Economics, Finance, Business, and Development (ICEFBD 2018). doi:10.25236/icefbd.18.080

Oskam, J. A. (2019). The Future of Airbnb and the Sharing Economy. doi:10.21832/9781845416744

Ozanne, L. K. (2019). Creating value to mitigate disaster harm: how the sharing economy can support consumers and policy makers. Handbook of the Sharing Economy, 254-265. doi:10.4337/9781788110549.00029

Pinson, P., Moret, F., Baroche, T., \& Papakonstantinou, A. (2020). Negotiation Approaches for Sharing Systems. Analytics for the Sharing Economy: Mathematics, Engineering and Business Perspectives, 151-171. doi:10.1007/978-3-030-35032-1_10

Saragih, S. P. (2015). Influence of Knowledge Sharing And Information Technology Innovation on Employees Performance at Batamindo Industrial Park. CommIT (Communication and Information Technology) Journal, 9(2), 45. doi:10.21512/commit.v9i2.359

Szemerédi, E., \& Tatay, T. (2020). Sharing communities - Community currency in the sharing economy. Society and Economy. doi:10.1556/204.2020.00027

Tussyadiah, I. P. (2016). Strategic Self-presentation in the Sharing Economy: Implications for Host Branding. Information and Communication Technologies in Tourism 2016, 695-708. doi:10.1007/978-3-319-282312_50

Weber, T. A. (2015). The Question of Ownership in a Sharing Economy. 2015 48th Hawaii International Conference on System Sciences. doi:10.1109/hicss.2015.578

Yeung, D. (2018). Social Media as a Catalyst for Policy Action and Social Change for Health and Well-Being: Viewpoint. Journal of Medical Internet Research, 20(3), e94. doi:10.2196/jmir.8508

YunSeungKo. (2014). A Study on Sharing Economy of the ICT development. The e-Business Studies, 15(6), $77-$ 100. doi:10.15719/geba.15.6.201412.77

\section{Appendices}

Database search results

\begin{tabular}{|l|c|c|}
\hline \multicolumn{1}{|c|}{ Search Expression } & Web of Science & Scopus \\
\hline Business Replica \& sharing & 288 & 259 \\
Capitalism \& sharing & 146 & 541 \\
Sharing Economy & 139 & 2 \\
Sharing Economies & 139 & 42 \\
Collective utilization & 49 & 14 \\
Peer-to-Peer Exchange & 25 & 21 \\
Product-service system \& sharing & 25 & 18 \\
Share Economy & 22 & 53 \\
Sustainable Utilization & 17 & 21 \\
Pooling resource \& Sharing & 17 & 24 \\
Social innovation \& sharing & 15 & 9 \\
Cooperative economy & 14 & 7 \\
Social Lending & 14 & 1 \\
Access-based utilization & 13 & 3 \\
Sharing replica \& Commercial & 5 & 1 \\
Alternative Utilization \& Sharing & 3 & 1 \\
Cooperative lifestyle & 2 & 14 \\
Commercial sharing systems & 2 & 1 \\
Expounded self \& sharing & 2 & 1143 \\
Market - mediated acquisition & 1 & \\
\hline
\end{tabular}

